\title{
¿Triunfo de la izquierda o de la derecha?
}

AQUiLes MONTOYA

Usamos el término izquierda para referirnos a las fuerzas políticas que están por el cambio y derecha para aquellos que se oponen al cambio, esto es, que están por la preservación del status quo: preservación del modelo neoliberal, con sus privatizaciones, dolarización, tratados de libre comercio a favor de unos pocos, desempleo y subempleo, salarios reales deprimidos, deterioro y contaminación del medio ambiente, corrupción e impunidad, etc.

Aparentemente el triunfo fue de la izquierda, en tanto que el FMLN obtuvo un mayor número de votos a su favor, conservó el control de municipios emblemáticos a pesar de los muchos esfuerzos desplegados por la derecha, tanto legales, como ilegales e inclusive, inmorales. Sin embargo, la derecha ganó el control de la Asamblea Legislativa y recuperó algunas alcaldías en poder de la izquierda, lo cual es mucho más grave de lo que parece, como veremos oportunamente.

Pero ¿qué nos dicen las elecciones? ¿Qué lectura o lecturas podemos hacer de las mismas? En primer lugar, observamos el ausentismo y, de manera particular, la poca participación de la juventud, todo lo cual es interesante en sí mismo, en tanto que nos revela el poco aprecio que la población tiene por uno de los elementos de la democracia representativa: las elecciones. Lo cual a menudo se interpreta como fruto de la pérdida de confianza en la clase política, en los partidos políticos. Yo me inclinaría más a pensar que el problema radica en que 
vivimos una forma de democracia en la cual la mayoría no cree, esto es, la democracia representativa. Si avanzáramos hacia una democracia participativa, seguramente, que las cosas serían diferentes. Si las personas observaran que sus opiniones cuentan porque son tomadas en cuenta por aquellos a quienes delegó el ejercicio del poder, seguramente que participarían masivamente y con gran entusiasmo y esperanzas. Pero en la medida que la población percibe que los políticos electos no pueden cambiar la realidad o sólo velan por sus intereses o por los intereses de los ricos y poderosos, no les entusiasma, ni les motiva el asistir a votar. Y si adicionalmente los políticos electos toman decisiones trascendentes sin consultar a la opinión pública, que ciertamente no puede reducirse a la opinión de unos cuantos medios de comunicación integrantes de la elite económica dominante, les resulta un sin sentido ejercer el sufragio. Muchas personas, de esas que no votan, piensan que es indiferente quien gane, en la medida que no alcanzan a ver de qué manera les beneficiaría directa o indirectamente el que gane la izquierda o la derecha. Por ejemplo, para quienes no cotizan al ISSS, o peor aún, para quienes ni siquiera tienen acceso a los servicios de salud, y que es una gran mayoría de la población, sobre todo en el área rural, el gran debate en torno a la privatización de la salud les resulta indiferente. Seguramente que si les preocupa y les interesa tener acceso a agua potable, pero los políticos les han prometido tantas veces en campaña que la tendrán y nunca les han cumplido, que ahora ya no creen. De allí que si la izquierda quiere avanzar hacia el cambio de la mentalidad colectiva y de la realidad, es necesario que demuestre con sus acciones, con su práctica diaria en los municipios ganados que es posible mejorar el presente y el futuro de la gente.

En el caso de la juventud, me refiero a un importante sector de la misma, la cuestión es todavía más grave, se trata de una población que no tiene fe en el futuro y que vive tan sólo el día a día con una actitud escapista, muy próxima a lo que yo denominaría un existencialismo no ilustrado. Pero es que cuando observamos la realidad nacional y mundial, se requiere de mucha fe en la humanidad, de rebuscar con mucha paciencia y diligencia los pequeños brotes de una nueva realidad que se va gestando lentamente, para tener esperanzas en el futuro. Labor de los intelectuales sería el hacer visibles esos minúsculos pimpollos de nueva realidad que van germinando a lo largo y ancho del 
mundo. ¿Pero se habrán enterado ya los intelectuales de esa nueva realidad? $¿ \mathrm{O}$ acaso su actitud acomodaticia o su existencialismo ilustrado no es más que una manifestación de su desesperanza? Durante los años ochenta hubo en el país muchos intelectuales que tenían esperanzas en el futuro, ¿qué se hicieron, a qué se dedican ahora, a qué les saben los platos de lentejas fruto de su involución?

En segundo lugar, los resultados obtenidos por el FMLN en los municipios de San Salvador, Santa Tecla, Soyapango y Santa Ana, han demostrado que cuando la población adquiere conciencia política e ideológica, de nada sirven ni los millones, ni las buenas imágenes de los candidatos de derecha, ni la actualización de las triquiñuelas del pasado: la compra de votos no ha funcionado. Esto es esperanzador en sí mismo. Desafortunadamente, la magnitud de esta población aún no es suficiente como para modificar la correlación de fuerzas en la Asamblea Legislativa y seguramente tampoco lo será para ganar el Ejecutivo. Todo lo cual está exigiendo de la izquierda una revisión de sus acciones, de sus tácticas y de sus estrategias. Se requiere de más trabajo político, de más formación teórica de sus cuadros y de más cercanía con la población.

Una tercera lectura de las elecciones nos muestra que la inmensa mayoría de los electores ha preferido a los partidos tradicionales, que los disidentes tanto de la derecha como de la izquierda no son apreciados por los ciudadanos y ciudadanas, lo cual a su vez nos indica que las diferencias que conducen a los intentos de crear nuevas fuerzas políticas, son más en el ámbito de las cúpulas que de las bases, aunque en algunos municipios tal fraccionamiento de la izquierda ha provocado pérdidas electorales o ha impedido derrotar a la derecha. Casos específicos de lo anterior lo observamos en algunos municipios del departamento de La Libertad, en donde debido a las acciones de los renovadores y a cierta línea cerrada del FMLN, se perdieron municipios y se dejaron de ganar otros por parte de la izquierda.

Una cuarta lectura nos indica que la mayoría de los votantes está a favor de la derecha, que el descontento con ARENA no es suficiente como para impulsar al elector desencantado hasta una posición de izquierda, prefieren seguir siendo derecha y quedarse en la sucursal de este partido: el PCN. Y es que de las pocas verdades que manifiesta el PCN, una de ellas es ser manifiestamente de derecha, lo cual significa

¿Tiunto de la izquierda o de la derecha? 
que más que defender los intereses de la mayoría de la población, defienden los suyos propios o los de los ricos y poderosos. Eso significa ser de derecha y no otra cosa, por eso el PCN se alinea con ARENA y quienes votan por el PCN, lo están haciendo también por ARENA. Esta realidad debería de ser suficientemente explícita, de tal manera que quienes honestamente votan por este partido, se desengañaran de una vez y para siempre. Votar por el PCN no es castigar a ARENA: es premiar a ARENA. Muchos electores, demasiados diría yo, le siguen temiendo a la izquierda, inclusive a una izquierda bastante moderada, como lo es el CDU. El fantasma del comunismo aún le sirve a la derecha. En la mentalidad colectiva aún pervive toda una serie de falacias que los medios de comunicación de derecha se encargaron de implantar en el pasado en las mentes de una población desinformada, poco crítica y tradicionalmente conservadora y que ahora es reforzada en cada evento electoral o cuanta vez lo creen necesario. Además de echar mano de las campañas de desprestigio contra las alcaldías del FMLN, como las emprendidas por El Diario de Hoy y secundadas por otros medios de comunicación cada vez menos objetivos, sesgados y por ello, pocos efectivos entre los sectores más conscientes de la población, pero no es posible decir lo mismo cuando se trata de algunos segmentos de la población rural desinformada y cuyas vidas y realidades parecieran ser ajenas a las decisiones políticas, económicas y sociales que toma la derecha desde el ejecutivo o el legislativo.

Una quinta lectura de las recién pasadas elecciones tiene que ver con el relativo éxito del CDU; sin embargo, éxito pírrico al fin, si se tiene en cuenta su posible nula incidencia en el que hacer legislativo, en tanto sus votos no contarán ni para decidir mayorías simples, ni calificadas. No obstante, nos parece que el CDU cuenta con algunos elementos a su favor que le permitirían seguir creciendo, cuales son: ser una izquierda moderada; contar entre sus integrantes a personas capaces, honorables y respetables, lo cual les posibilitaría captar un segmento importante de las capas medias que ahora no encuentran donde ubicarse políticamente; su tipo de propuestas tienden a ser racionales y convincentes, etc. El CDU podría convertirse en un partido de cuadros intelectuales y profesionistas, semejante a aquel MNR del Dr. Ungo. Seguramente necesitan unificar su ideología social cristiana, a fin de tener su propia identidad. Ahora bien, para capitalizar 
sus elementos favorables es, obviamente, imprescindible tener presencia a escala nacional y de manera permanente. En las condiciones actuales de El Salvador y del mundo, la existencia de un partido del talante del CDU no sólo es importante sino que es necesario, la realidad lo exige.

Una lectura final de las elecciones tiene que ver con la pérdida de algunas alcaldías por parte del FMLN, pérdida que en parte se explica por la escisión de los renovadores, los cuales dividieron el voto de la izquierda y posibilitaron que ganara la derecha. Realidad que viene a explicar el apoyo que los medios de comunicación del régimen brindaron al principal dirigente renovador, afortunadamente para la izquierda de El Salvador, la inmensa mayoría de las bases del FMLN, evidenció en las urnas su rechazo a los disidentes renovadores, como en el pasado lo hizo con los seguidores de Villalobos.

Pero, ¿por qué calificamos de grave la pérdida de municipalidades por parte del FMLN? En primer lugar, porque una forma de convencer a la población de que no existen razones fundadas para temerle al Frente, es demostrando a través de la práctica que no comen niños, que no destruyen la familia, que no están contra los cristianos, que no racionan los alimentos, que no quitan casas, ni tierras, ni bueyes, ni nada, que de lo que se trata es de construir una sociedad donde exista seguridad económica y social para todos, además de una auténtica democracia. En segundo lugar porque un consejo municipal del Frente debe de evidenciar mediante obras a favor de la población que el Frente si está por la gente, lo cual posibilitaría continuidad en el ejercicio del poder municipal. Cuando la gente no reelige a una planilla propuesta por el Frente es porque no se ha logrado demostrar en la práctica que el Frente si trabaja para la gente, lo cual es muy grave.

La pérdida de municipalidades por parte del Frente, significa no sólo una derrota electoral. Es mucho más serio que eso, en tanto se frena la desmistificación del Frente y a su vez, la gente pierde la confianza en que es posible construir un futuro mejor de la mano con el Frente.

De cara al nuevo período es preciso que las autoridades municipales del Frente, reelectas o las recién electas, tengan en mente que es preciso evidenciar con transparencia y honestidad lo que significa ser farabundista. Un funcionario del Frente, elegido popularmente, cier-

¿Tinunto de la izquierda o de la derecha? 
tamente, también es un ser humano, pero lo que debería hacer la diferencia entre él y cualquiera otro, es su conducta intachable, su nobleza, su solidaridad y su espíritu revolucionario. De actuar así, la reelección debería de estar asegurada. Adicionalmente, en los municipios controlados por el frente debería de existir una preocupación y ocupación por la formación político ideológica de una masa crítica de sus cuadros, que haga posible contrarrestar entre la población menos politizada los efectos de la propaganda del régimen.

Para quienes consideramos que los cimientos de la nueva sociedad se tienen que ir construyendo en los espacios municipales es de suma trascendencia el que la izquierda gane alcaldías y que aquellas ganadas se conserven, porque la gente ha visto la diferencia entre un gobierno municipal farabundista y cualquier otro. Cuando hablamos de construir los cimientos de una nueva sociedad, obviamente, esto exige un cambio en el trabajo tradicional de las municipalidades, e implica ocuparse de aspectos económicos vinculados a la producción, a la comercialización y al financiamiento, además de la capacitación técnica. Así como también de aspectos sociales relacionados con el acceso a agua potable, energía eléctrica, comunicaciones, educación y salud. Pero de igual manera ocuparse de aspectos vinculados con la cultura: bibliotecas, talleres de danza, música, etc. casas de la cultura, ludotecas, etc. y principalmente, de la motivación en cuanto a la práctica de nuevos valores, tales como la cooperación, la solidaridad, la unidad, etc.

Por tal razón es que nos parece que el Frente debería de compartir entre todos sus consejos municipales las experiencias de, al menos, tres municipios que desde nuestra perspectiva son ejemplares, tales son: Nejapa, Suchitoto y Tecoluca.

Desde esta perspectiva la importancia que puede tener el control de municipios grandes es diferente a la de los pequeños, donde la mayoría de la población es rural y requieren de mayor apoyo, porque mayores son sus carencias. Esto lo puede hacer el Frente, con el apoyo internacional, pero sobre todo con la participación de la población. Pero para que la población participe es necesario que esté organizada, organización que posibilita la concientización y el entusiasmo en la participación.

Ante la pobreza y la exclusión que genera el capitalismo en la actual fase de globalización, la respuesta de la población organizada es el 
Desarrollo Económico Comunitario, ciertamente, para avanzar en esta línea de trabajo no es condición imprescindible el contar con el control municipal por parte del Frente, pero resulta mucho más fácil cuando las autoridades municipales no sólo no se oponen a los esfuerzos de la población organizada, sino que promueven, apoyan y buscan recursos financieros en el exterior a fin de avanzar dentro de esta alternativa popular de desarrollo.

¿Triunto de la izquierda o de la derecha? 